\title{
V
}

\section{PERCEPÇÕES SOBRE A UTILIZAÇÃO DE ATIVIDADES PRÁTICAS/EXPERIMENTAIS EM CIÊNCIAS NOS ANOS INICIAIS DA EDUCAÇÃO DE JOVENS E ADULTOS (EJA)*}

\author{
Hellen Jannisy Vieira Beiral
}

Neste capítulo apresento um panorama geral da pesquisa "O uso da experimentação escolar em Ensino de Ciências como prática pedagógica na Educação de Jovens e Adultos", desenvolvida nos anos de 2016 a 2018, durante o período de pós-doutoramento na Linha de Pesquisa Diversidade, Desigualdade Social e Educação (DDSE) do Programa de Pós-Graduação em Educação da Universidade Federal Fluminense (UFF), junto ao Núcleo de Estudos e Documentação sobre a Educação de Jovens e Adultos (NEDEJA), em parceria com o Núcleo de Apoio Experimental em Bioquímica para o Ensino de Ciências e Biologia $(\mathrm{NAEB})^{2}$ da Universidade do Estado do Rio de Janeiro (UERJ) e com a Fundação Municipal de Educação do município de Niterói (RJ). A principal questão da pesquisa contemplava compreender como o uso de atividades práticas/experimentais ${ }^{3}$ no Ensino de Ciências nos anos iniciais da EJA era trabalha-

${ }^{*}$ DOI - 10.29388/978-65-86678-41-3-0-f.111-134

${ }^{1}$ Doutorado em Ciência e Pós-doutorado em Educação de Jovens e Adultos. Professora adjunta da Faculdade de Formação de Professores da Universidade do Estado do Rio de Janeiro na área de Bioquímica e Química.

${ }^{2} \mathrm{O}$ NAEB, coordenado por mim, foi estruturado como um projeto de ensino, pesquisa e extensão da Faculdade de Formação de Professores (FFP/UERJ) no ano de 2015, tendo por objetivo focalizar o processo de elaboração e realização de experimentos para a disciplina de Bioquímica do curso de Licenciatura em Ciências Biológicas da FFP/UERJ. E, ainda, tendo como propósito a mediação destes experimentos didáticos do ensino superior para experimentos didáticos escolares, possibilitada pela articulação com as disciplinas voltadas para os Métodos e Ensino de Biologia, obrigatórias do curso de licenciatura em Ciências Biológicas da FFP e ministradas por docentes da área de ensino (Beiral et al 2016).

${ }^{3} \mathrm{O}$ termo "atividades práticas/experimentais" neste artigo compreende todas as atividades desenvolvidas no ambiente escolar ou fora deste, que estimulem e contribuem para o desenvolvimento das habilidades características do método científico. Estas são, como especificado por Dourado (2001), atividades de observação/interpretação de determinado fenômeno, capazes de formular e testar hipóteses plausíveis, de recolher informações e problematizá-las e de argumentar. Mas também se incluem atividades que motivem atitudes como curiosidade, dúvida, empenho, responsabilidade, respeito pelo outro e reflexão compartilhada que se concretizam nas tipologias Trabalho Prático (jogos, trilhas, enigmas entre outros), Trabalho Laboratorial, Trabalho de Campo, Trabalho Experimental e Visitas Interativas a Espaços de Divulgação Científica. 
do no currículo, com especial atenção às práticas pedagógicas realizadas nas escolas do município de Niterói que ofertavam esta modalidade de ensino.

O primeiro diagnóstico sobre as práticas pedagógicas dos professores que atuavam na EJA, na ocasião da pesquisa, mostrou que o Ensino de Ciências se configurava, na maior parte das situações, como uma atividade isolada ou não articulada com o currículo imaginado. Nesse sentido, a intervenção nas aulas de Ciências se postava como uma forma colaborativa aos docentes, que eram estimulados a propor e executar atividades práticas/experimentais que se articulassem com os conteúdos postos nos currículos para a EJA - fenômeno que se tornou um dos objetivos da pesquisa. Toda a escrita deste texto, portanto, será norteada pela seguinte interrogação: quais foram as percepções do ensino de Ciências nos anos iniciais da EJA, considerando a conjuntura em que esta modalidade de ensino se insere?

Faço a escolha de utilizar a palavra "percepções" porque considero a necessidade de mais investimentos, tanto no campo teórico quanto de tempo de desenvolvimento da pesquisa, para se avaliar, de forma mais efetiva, os impactos desta na mudança de cultura do cotidiano escolar nos anos iniciais da EJA, no que se refere ao Ensino de Ciências. No entanto, o uso da palavra "conjuntura" na interrogação, está imbuído do seu significado mais evidente: o conjunto de fatores que emergem em um determinado contexto, sejam eles no âmbito das conquistas legais, na formação docente específica; seja nas práticas pedagógicas e nos desdobramentos destes três eixos centrais.

Conjuntura também nos remete a um determinado cenário, momento, condição ou circunstância específica, sinônimos estes que nos direcionam para reflexões sobre os desafios que precisam ser enfrentados na articulação de estratégias de acesso, reinserção e permanência dos jovens, adultos e idosos na sala de aula (PRATA; MARTINS, 2005; MOURA, 2009). Dentre os desafios, destacam-se a constituição de classes heterogêneas (faixa etária, gênero, profis são, classe econômica, anseios e perspectivas de vida, etc.) (GARCIA; DA SILVA, 2018) e sujeitos com ritmo escolar próprio, caracterizado muitas vezes pela sua experiência de vida (CAMARGO, 2005; PICONEZ, 2006), que demandam uma apreciação singular na organização da escola quanto à flexibilidade de horários, às formas de seleção e trabalho dos conteúdos, assim como aos modos de se processar as avaliações.

Considerando que a dinâmica de percepção de uma determinada conjuntura não acontece de forma espontânea ou ingênua, e que uma mesma conjuntura pode ser percebida por infinitos modos de reconhecimento, destaco a 
seguir as etapas metodológicas que permitiram categorizar as percepções obtidas por esta pesquisa de intervenção nos anos inicias da EJA, a qual se deu de forma negociada - uma pesquisa, portanto, de caráter colaborativo e participativo entre os sujeitos integrantes.

\section{Construção das etapas metodológicas da pesquisa}

\subsection{Reconhecimento e conhecimento dos sujeitos envolvidos}

Nesta pesquisa estiveram envolvidos 41 professores atuantes na EJA do município de Niterói (RJ), sendo 31 destes pedagogos, três licenciados em Biologia, um licenciado em Química e seis professores de Educação Artística. Também participaram nove pedagogos gestores da EJA nas escolas participantes. Entre os integrantes do NEDEJA, foram dois professores doutores da área de educação e nove professores doutores do NAEB, das áreas de Ciências Biológicas e de Ensino de Ciências. A pesquisa contou ainda com uma técnica de nível superior, bolsista do Programa de Apoio Técnico às Atividades de Ensino, Pesquisa e Extensão (PROATEC/UERJ), e nove monitores, sendo oito licenciandos do curso de Ciências Biológicas e um do curso de licenciatura em Pedagogia, ambos da FFP/UERJ. Entre os monitores havia uma bolsista de extensão e uma bolsista de Iniciação à docência, cujos recursos estavam vinculados ao NAEB. E, por fim, somava-se ao grupo sete estagiários remunerados pela Fundação Municipal de Educação de Niterói.

Ao final, foram sujeitos da pesquisa 422 alunos de nove escolas do respectivo município fluminense, matriculados na modalidade de ensino EJA, e que estavam cursando do primeiro ao quinto ano do ensino fundamental - sendo a maioria não letrada e os demais semiletrados.

\subsection{Observação das práticas pedagógicas}

No desenvolvimento desta pesquisa, o termo "práticas pedagógicas" foi entendido como todas as ações educativas que aconteceram nas classes dos anos inicias do ensino fundamental da EJA do município de Niterói, ocorridas no espaço físico de sala de aula ou em outro ambiente escolar (laboratórios de Ciências, Bibliotecas, pátios, quadras poliesportivas), incluindo também as ações educativas que ocorreram em espaços para além dos muros da escola, tais como visitas a espaços de divulgação científica e a centros universitários - e que 
envolveram professores atuantes e em formação, gestores educacionais e os estudantes da EJA.

A observação das práticas pedagógicas se deu em dois momentos: um primeiro sem intervenção ativa, apenas com a observação dos sujeitos e o contexto em que estes estavam envolvidos durante as aulas; e, um segundo, em que a intervenção nas práticas pedagógicas se consolidou ativamente. O processo de intervenção ativa foi compreendido como o espaço/tempo da pesquisa em que o contexto estudado nas investigações foi interferido pelo pesquisador de forma intencional, motivando transformações na cultura das práticas pedagógicas ou inserindo concretamente no campo da pesquisa, novas abordagens para suscitar mudanças específicas ou mais amplas a estas práticas (MEGID, 1999; ROCHA, 2006).

\subsection{Processo de intervenção ativa: favorecimento de subsídios para mu- danças nas práticas pedagógicas}

O processo de intervenção ativa se materializou através de ciclos de discussões (BOGDAN; BIKLEN, 1994) para planejar e sistematizar toda a dinâmica das ações que foram realizadas, com o intuito de articular conteúdos de Ciências através do uso de atividades práticas/experimentais com aqueles conteúdos inerentes às disciplinas específicas de Língua Portuguesa e Matemática. Também foi dada a devida importância às relações com o cotidiano dos jovens e adultos.

Os ciclos de discussões se constituíram por reuniões quinzenais entre a equipe do NAEB, formada pelos docentes universitários das áreas de Ensino e Metodologias em Ciências e Bioquímica e pelos licenciandos em Biologia e Pedagogia, os pesquisadores do NEDEJA, os professores e gestores das escolas. Nesta etapa, dois pontos foram priorizados, o planejamento proposto pelo professor e a Portaria FME N ${ }^{\circ}$ 085/2011 que institui o referencial curricular para o ensino fundamental e para a EJA, presente nas diretrizes curriculares do município de Niterói.

A construção do processo de intervenção ativa nos ciclos de discussões ocorreu conforme a sequência dos itens que seguem abaixo:

1. Diálogo com os professores sobre os conceitos de Ciências que pretendiam que os alunos compreendessem; 
2. Os conceitos selecionados foram revisitados criticamente junto aos professores para decidir quais articulações com o dia a dia dos alunos poderiam ser feitas;

3. Elaboração de atividades práticas/experimentais em Ciências e/ou seleção de atividades práticas/experimentais disponíveis publicamente (mídia digital e impressa) e aqueles que faziam parte do acervo do NAEB;

4. Utilização das atividades práticas/experimentais nas aulas de Ciências na EJA.

Um total de 214 atividades práticas/experimentais em Ciências foram realizadas nas intervenções que ocorreram uma ou duas vezes por semana, em cada uma das nove escolas que atendiam a modalidade de ensino EJA em Niterói/RJ, no ano de 2017. O número destas intervenções foi ampliado para 413 no ano de 2018, contribuindo para uma melhor avaliação das percepções sobre o ensino de Ciências nos anos iniciais da EJA no município de Niterói.

\subsection{Diários de campo}

Denominei "diário de campo" o registro escrito em caderno, para documentar as práticas pedagógicas nas classes dos anos iniciais da EJA. O diário foi construído com informações do ambiente escolar e também das atividades realizadas fora deste cenário.

Preferencialmente, os registros foram produzidos no momento em que as ações estavam sendo experienciadas no campo, para que a captura de algumas falas, expressões corporais e sentimentos não se perdessem na memória.

Pensando na complexidade da estrutura da pesquisa, mais especificamente nos sujeitos envolvidos (cada intervenção foi realizada por um integrante diferente do NAEB e em cada escola o corpo docente variava) e no campo da pesquisa (cada escola tinha uma dinâmica própria, localiza-se em um território diferente e o perfil dos estudantes variava muito), foi percebida a necessidade de padronizar os registros em duas categorias: descritiva e analítico reflexiva conforme sugerido em Lima et al (2007). Para cada categoria definida foi organizado um roteiro baseado nos estudos e orientações de Bogdan \& Biklen (1994, p. 163-165) sobre registros em diários de campo. As tabelas 1 e 2 abaixo, apresentam esses dois roteiros utilizados nas intervenções das práticas pedagógicas nos anos inicias da EJA. 


\begin{tabular}{|c|c|}
\hline \multicolumn{2}{|c|}{ TABELA 1 - ROTEIRO PARA A CATEGORIA DESCRITIVA } \\
\hline ASPECTOS & DESCRIÇÃO \\
\hline Estudantes da EJA & $\begin{array}{l}\text { Quantidade de homens e mulheres, idades aproximadas, } \\
\text { profissão. }\end{array}$ \\
\hline Não estudantes da EJA & $\begin{array}{l}\text { Professores da EJA, Professores e demais integrantes do } \\
\text { NAEB e NEDEJA, gestores, estagiários. }\end{array}$ \\
\hline Ambiente Físico & $\begin{array}{l}\text { Ambiente escolar: sala de aula, laboratório de Ciências, bi- } \\
\text { blioteca e etc. } \\
\text { Ambiente fora da escola: espaço de divulgação científica, } \\
\text { centro universitário e etc. }\end{array}$ \\
\hline $\begin{array}{l}\text { Descrição da prática } \\
\text { pedagógica }\end{array}$ & $\begin{array}{l}\text { Relatar detalhadamente o desenvolvimento da prática pe- } \\
\text { dagógica, do comportamento dos envolvidos, reações que } \\
\text { se expressam na fala, no silêncio, nos gestos, nos olhares e } \\
\text { etc. }\end{array}$ \\
\hline $\begin{array}{l}\text { Relatos que antecede- } \\
\text { ram e sucederam a } \\
\text { prática pedagógica }\end{array}$ & $\begin{array}{l}\text { Conversas entre os estudantes da EJA e/ou destes com } \\
\text { os demais envolvidos, sobre a intervenção. Diálogo entre } \\
\text { os não estudantes da EJA. }\end{array}$ \\
\hline
\end{tabular}

\begin{tabular}{|c|c|}
\hline \multicolumn{2}{|c|}{ TABELA 2 - ROTEIRO PARA A CATEGORIA ANALÍTICO-REFLEXIVA } \\
\hline ASPECTOS & ESCRITOS \\
\hline $\begin{array}{l}\text { Reflexão sobre os Ci- } \\
\text { clos de discussões }\end{array}$ & $\begin{array}{l}\text { Questões levantadas após leitura da bibliografia sugerida } \\
\text { aos professores da EJA sobre: o processo de intervenção } \\
\text { em suas aulas; os conteúdos de Ciências e suas conexões } \\
\text { com o currículo; insegurança em utilizar atividades práti- } \\
\text { cas/experimentais; possíveis contribuições da intervenção } \\
\text { para o letramento e alfabetização. }\end{array}$ \\
\hline $\begin{array}{l}\text { Reflexão sobre a esco- } \\
\text { lha dos temas geradores }\end{array}$ & $\begin{array}{l}\text { Percurso da construção de metodologias para escolher o } \\
\text { tema gerador da intervenção. }\end{array}$ \\
\hline $\begin{array}{l}\text { Reflexão sobre o plane- } \\
\text { jamento e execução das } \\
\text { práticas pedagógicas }\end{array}$ & $\begin{array}{l}\text { Correlação das Diretrizes e os Referenciais Curriculares e } \\
\text { Didáticos para a EJA de Niterói presentes na portaria } \\
\text { FME N }{ }^{\circ} 085 / 2011 \text { com as atividades práticas/experimen- } \\
\text { tais propostas; Estratégias para inserir o conteúdo das dis- } \\
\text { ciplinas Português e Matemática nas atividades práticas/ } \\
\text { experimentais considerando suas articulações com o coti- } \\
\text { diano e interesse do estudante da EJA; Participação na } \\
\text { construção de procedimentos técnico-científicos, de ma- } \\
\text { teriais e manuseio destes para as atividades práticas/expe- } \\
\text { rimentais. }\end{array}$ \\
\hline $\begin{array}{l}\text { Reflexão sobre a apro- } \\
\text { priação científica }\end{array}$ & $\begin{array}{l}\text { Constituição de possibilidades alternativas de proporcio- } \\
\text { nar ao estudante da EJA não alfabetizado a aquisição da }\end{array}$ \\
\hline
\end{tabular}




\begin{tabular}{|c|c|}
\hline & cultura científica. \\
\hline $\begin{array}{l}\text { Reflexão sobre a for- } \\
\text { mação docente inicial e } \\
\text { continuada }\end{array}$ & $\begin{array}{l}\text { Pontuar as modificações ocorridas nas práticas pedagógi- } \\
\text { cas dos professores da EJA decorrentes da intervenção } \\
\text { ativa; A intervenção ativa como um espaço promotor de } \\
\text { relações diretas entre teorias e práticas interdisciplinares } \\
\text { durante a formação do professor. }\end{array}$ \\
\hline
\end{tabular}

\subsection{Relatos de experiência}

A riqueza das descrições e dos escritos do diário de campo conduziu quase que intuitivamente o despertar para a produção de relatos de experiências. Os relatos foram elaborados pelos licenciandos em Biologia, pelos integrantes dos núcleos de pesquisa (NAEB e NEDEJA), que experienciaram ao menos 12 intervenções ativas, além dos estudos nos ciclos de discussões que precederam e sucederam estas intervenções.

A estruturação do conteúdo do relato seguiu um mesmo modelo, visando ser objeto de publicação futuramente. O modelo incluiu: a) identificação da experiência; b) introdução; c) desenvolvimento; e d) conclusão, estrutura característica desta escrita científica. Ainda foi solicitado aos licenciandos que nos relatos aparecessem os aspectos que consideravam significativos para a evolução de sua prática docente ainda em formação, destacando pontos positivos ou negativos da relação entre a teoria desenvolvida no curso de Licenciatura em Biologia e a sua aplicação na prática pedagógica nos anos inicias da EJA.

Considerando a importância de se documentar uma ação inovadora para o campo de pesquisa no ensino de Ciências na EJA, sobretudo nos anos iniciais, os instrumentos metodológicos de coleta de dados - diários de campo e relatos - permitiram uma melhor compreensão e compartilhamento dos processos interventivos que fundamentaram as percepções que serão a seguir detalhadas.

\section{Percepções sobre o Ensino de Ciências nos anos iniciais da EJA e seus desdobramentos}

$\mathrm{Na}$ intervenção não ativa, na qual os integrantes do NAEB e NEDEJA se colocaram na posição de meros observadores/espectadores das práticas pedagógicas ocorridas nas classes de EJA, revelou-se que estas práticas, de forma unânime, priorizavam o ensino de Português e Matemática justificado pela importância do letramento e da aplicação dos conteúdos matemáticos no dia a dia. 
As percepções emergidas deste primeiro diagnóstico evidenciaram o quanto a EJA ainda se apresenta marginalizada pelo conhecimento científico. Enquanto hoje a inserção de conteúdos de Ciências e seus diversos métodos de ensino são amplamente discutidos na educação infantil e nos anos iniciais do ensino regular (MEGID, 1999; CARVALHO; GIL-PÉRES, 2006; GOMES, 2009; NASCIMENTO, 2010), para os jovens e adultos neste mesmo nível escolar e que experienciam uma relação diária com os processos e produtos gerados pela relação Ciência-Tecnologia-Sociedade-Ambiente (MUENCHEN; AULER, 2007; CACHAPUS et al., 2008; SÁ et al., 2011) de forma bem mais densa que uma criança, esta mesma discussão não se cumpre na escola e nem no campo das pesquisas acadêmicas.

A não realização de práticas pedagógicas no ensino de Ciências nos anos iniciais da EJA, representada nos escritos dos diários de campo, foi o que impulsionou a pesquisa para o seu primeiro desdobramento: conhecer o que já foi realizado por outros pesquisadores, para obter uma ideia precisa sobre o estado atual dos conhecimentos relacionados ao tema e suas lacunas. Sendo assim, embebidos pela oportunidade da relação muito próxima entre as escolas e a academia, proporcionada pela confiança e interesse no desenvolvimento da pesquisa, tanto pelos pesquisadores envolvidos quanto para um vislumbramento de mudanças nas políticas públicas voltadas para a melhoria na qualidade do ensino da EJA no município de Niterói, os estudos gerados nos e a partir dos ciclos de discussões - etapa metodológica já descrita acima - foram o estrado para a constatação da inexistência do tema na literatura.

No sentido de não estagnar as percepções sobre o ensino de Ciências nos anos iniciais da EJA em uma região consolidada e entendendo que este artigo tem grande potencial de trazer vastas contribuições para o campo de pesquisa na área, opto por demonstrar os resultados obtidos a partir das análises e reflexões motivadas pelos escritos nos diários de campo.

\subsection{Identificação da literatura}

De início, foi feita uma busca no Banco de Teses e Dissertações da CAPES (Coordenação de Aperfeiçoamento de Pessoal de Nível Superior) usando o descritor ${ }^{4}$ "Ensino de Ciências na EJA". Para os trabalhos identificados pelo descritor escolhido, subdescritores como "Experimentação", "Atividades práticas", "Anos iniciais" e "Séries iniciais" foram posteriormente utilizados. O

${ }^{4}$ Descritor: parâmetro de registros de dados que possibilita que todos os registros referentes a um mesmo assunto sejam recuperados conjuntamente em mídia digital. 
resultado da pesquisa indicou que nenhuma tese ou dissertação foi produzida nos últimos dez anos sobre "Experimentação em Ciências nos anos iniciais da EJA". A última busca foi realizada em 30 de setembro de 2017.

Como teses e dissertações pressupõem tempo para a sua elaboração e que durante o processo de escrita até a conclusão destes trabalhos acadêmicos, capítulos podem se transformar em artigos científicos, surgiu o interesse nos ciclos de discussões em investigar o descritor e os subdescritores citados acima em revistas brasileiras indexadas, no período de 2007 a 2017.

As revistas escolhidas para consulta estão entre as que possuem maior visualização por pesquisadores da área de Ensino e Educação em Ciências: Alexandria: Revista de Educação em Ciência e Tecnologia; Ciência \& Educação; Ciência \& Ensino; Ciência em Tela; Ensaio: Pesquisa em Educação em Ciências; Experiências em Ensino de Ciências; Investigações em Ensino de Ciências; Revista Brasileira em Ensino de Ciências e Tecnologia; Revista Brasileira de Pesquisa em Educação em Ciências. Mais uma vez, foi confirmada a ausência de pesquisas sobre o tema. Nenhum artigo científico foi produzido nos últimos dez anos sobre o uso da experimentação em Ciências nos anos iniciais da EJA.

$\mathrm{Na}$ tentativa de encontrar trabalhos mais embrionários que se relacionavam com o tema e de entender um pouco mais sobre a EJA como espaço de ensino e de produção de conhecimento, foi utilizado como base para as buscas dos mesmos descritores e subdescritores, as publicações nos anais dos últimos três eventos principais da área de Educação e Ensino de Ciências e Biologia no Brasil: Reunião Nacional da Associação Nacional de Pós-Graduação e Pesquisa em Educação (ANPEd), Encontro Nacional de Pesquisa em Educação em Ciências (ENPEC) e Encontro Nacional de Ensino de Biologia (ENEBIO). O resultado da busca apontou para a ausência de resumos nestes eventos que se relacionavam com o tema de interesse.

Não é conveniente, portanto, relacionar a falta de pesquisas na área com a ausência do ensino de Ciências nos anos iniciais da EJA, mas é possível inferir que se não há propostas efetivas de inserção de conceitos científicos na prática pedagógica dos professores atuantes nessa modalidade de ensino, não geram visibilidade e consequente interesse acadêmico.

\subsection{Percepções sobre a prática docente}

A prática docente apesar de ser caracterizada por diversas tendências pedagógicas, cada professor, imbuído da aproximação de concepções ainda du- 
rante a sua formação e em conjunto com as que lhe são apresentadas ao longo de sua formação continuada, se apropria de uma determinada abordagem pedagógica que se reflete nas suas práticas educativas.

Apesar de vários autores utilizarem terminologias diferentes para caracterizar as práticas educativas no Brasil (PERRENOUD, 1997), nesta pesquisa, lanço mão dos estudos de Fahl (2003) como referencial teórico que subsidiaram a categorização das práticas pedagógicas percebidas nos escritos dos diários de campo, analisadas e refletidas nos ciclos de discussões. O trabalho de Fahl (2003) guarda relação com esta pesquisa por caracterizar práticas pedagógicas no Ensino de Ciências.

Dentre as abordagens pedagógicas percebidas com mais frequência na prática docente durante o período de observação - ainda antes do processo interventivo - e na intervenção ativa, estão aquelas que se aproximam do: (i) Modelo Construtivista; (ii) Modelo Ciência-Tecnologia-Sociedade (CTS) e do (iii) Modelo Sociocultural.

Considerando que no contexto do cotidiano escolar, modelos e tendências de práticas docentes adquirem novas caracterizações, também foram percebidas abordagens pedagógicas que evidenciaram a coexistência dos modelos acima descritos.

Interessante ressaltar que mesmo antes da intervenção ativa, foi percebido um esforço para que a prática docente não tendesse ao Modelo Tradicional "puro", que segundo Fahl (2003), consiste num processo de recepção passiva dos conteúdos curriculares, enfatizando a memorização dos conceitos através da clara relação vertical entre professor/aluno, marcada por aulas expositivas como sendo a principal metodologia de ensino utilizada.

As percepções relacionadas às práticas docentes voltadas especificamente para o Ensino de Ciências se deram no contexto da intervenção ativa, uma vez que os conteúdos de Ciências passaram a contemplar o processo educativo nos anos iniciais da EJA nas escolas do Município de Niterói somente a partir desta intervenção.

Nesse sentido, durante a construção do planejamento das aulas, características como: metodologia de ensino e aprendizagem; relação professor/aluno e tipo de avaliação - presentes nos diários de campo e nos relatos de experiência subsidiaram a classificação das práticas docentes nas três abordagens mais percebidas. A tabela 3 apresenta um panorama geral dessa organização. 
TABELA 3 - CARACTERÍSTICAS QUE APROXIMARAM A PRÁTICA DOCENTE AO MODELO CONSTRUTIVISTA

\begin{tabular}{|c|c|c|c|}
\hline $\begin{array}{l}\text { Objetivo geral } \\
\text { do planejamen- } \\
\text { to }\end{array}$ & $\begin{array}{l}\text { Metodologia de en- } \\
\text { sino e aprendiza- } \\
\text { gem }\end{array}$ & $\begin{array}{l}\text { Relação } \\
\text { professor/aluno }\end{array}$ & $\begin{array}{l}\text { Tipo de avalia- } \\
\text { ção }\end{array}$ \\
\hline $\begin{array}{l}\text { Motivar e incen- } \\
\text { tivar o estudante } \\
\text { da EJA a elabo- } \\
\text { rar a construção } \\
\text { dos conceitos } \\
\text { em Ciências para } \\
\text { ampliação do } \\
\text { seu conhecimen- } \\
\text { to }\end{array}$ & $\begin{array}{l}\text { Atividades práticas/ } \\
\text { experimentais inves- } \\
\text { tigativas que prioriza- } \\
\text { ram soluções de pro- } \\
\text { blemas }\end{array}$ & $\begin{array}{l}\text { O professor foi o } \\
\text { mediador no proces- } \\
\text { so de construção dos } \\
\text { conceitos inerentes } \\
\text { às atividades práti- } \\
\text { cas/experimentais } \\
\text { desenvolvidas pelos } \\
\text { estudantes da EJA }\end{array}$ & $\begin{array}{l}\text { Autoavaliação, } \\
\text { considerando o } \\
\text { conhecimento } \\
\text { sobre os concei- } \\
\text { tos científicos } \\
\text { antes do desen- } \\
\text { volvimento das } \\
\text { atividades e o } \\
\text { que cada estu- } \\
\text { dante alcançou }\end{array}$ \\
\hline
\end{tabular}

CARACTERÍSTICAS QUE APROXIMARAM A PRÁTICA DOCENTE AO MODELO CIÊNCIA-TECNOLOGIA-SOCIEDADE (CTS)

\begin{tabular}{|c|c|c|c|}
\hline $\begin{array}{l}\text { Objetivo geral } \\
\text { do planejamen- } \\
\text { to }\end{array}$ & $\begin{array}{l}\text { Metodologia de en- } \\
\text { sino e aprendiza- } \\
\text { gem }\end{array}$ & $\begin{array}{l}\text { Relação } \\
\text { professor/aluno }\end{array}$ & $\begin{array}{l}\text { Tipo de avalia- } \\
\text { ção }\end{array}$ \\
\hline $\begin{array}{l}\text { Relacionar o } \\
\text { conteúdo de } \\
\text { Ciências com o } \\
\text { desenvolvimen- } \\
\text { to científico e } \\
\text { tecnológico de } \\
\text { forma contextu- } \\
\text { alizada e indisso- } \\
\text { ciável dos im- } \\
\text { pactos socioam- } \\
\text { bientais }\end{array}$ & $\begin{array}{l}\text { Atividades práticas/ } \\
\text { experimentais geral- } \\
\text { mente em grupo, cu- } \\
\text { jos conceitos científi- } \\
\text { cos eram sempre } \\
\text { abordados de forma } \\
\text { a desenvolver uma } \\
\text { conscientização para } \\
\text { a ação social respon- } \\
\text { sável }\end{array}$ & $\begin{array}{l}\text { Professor atuou } \\
\text { como colaborador, } \\
\text { levantando questões } \\
\text { polêmicas, e como } \\
\text { mediador dos conte- } \\
\text { údos e suas relações } \\
\text { perversas e/ou be- } \\
\text { néficas para a socie- } \\
\text { dade }\end{array}$ & $\begin{array}{l}\text { Avaliação } \\
\text { contínua do } \\
\text { aprendizado } \\
\text { crítico, não } \\
\text { ingênuo } \\
\text { durante as } \\
\text { atividades } \\
\text { propostas }\end{array}$ \\
\hline
\end{tabular}

CARACTERÍSTICAS QUE APROXIMARAM A PRÁTICA DOCENTE AO MODELO SOCIOCULTURAL

\begin{tabular}{|c|c|c|c|}
\hline $\begin{array}{l}\text { Objetivo geral } \\
\text { do planejamen- } \\
\text { to }\end{array}$ & $\begin{array}{l}\text { Metodologia de } \\
\text { ensino e aprendi- } \\
\text { zagem }\end{array}$ & $\begin{array}{l}\text { Relação } \\
\text { professor/aluno }\end{array}$ & $\begin{array}{l}\text { Tipo de avalia- } \\
\text { ção }\end{array}$ \\
\hline $\begin{array}{l}\text { Evidenciar os } \\
\text { conceitos cien- } \\
\text { tíficos presentes } \\
\text { no dia a dia do } \\
\text { estudante da } \\
\text { EJA e motivar o } \\
\text { seu entendimen- } \\
\text { to a partir do } \\
\text { contexto socioe- } \\
\text { conômico, políti- } \\
\text { co e cultural }\end{array}$ & $\begin{array}{l}\text { Atividades } \\
\text { práticas/experimen- } \\
\text { tais inovadoras ou } \\
\text { renovadas para o } \\
\text { contexto da EJA, } \\
\text { pensadas a partir de } \\
\text { um tema gerador de } \\
\text { interesse do estudan- } \\
\text { te. Visitação a espa- } \\
\text { ços culturais e cien- } \\
\text { tíficos }\end{array}$ & $\begin{array}{l}\text { Relação horizontal, } \\
\text { consolidada pelo } \\
\text { compartilhamento } \\
\text { de experiência de } \\
\text { vida }\end{array}$ & $\begin{array}{l}\text { Durante o pro- } \\
\text { cesso. Através } \\
\text { da identificação } \\
\text { de conceitos } \\
\text { curriculares em } \\
\text { desenhos e na } \\
\text { narração de fa- } \\
\text { tos cotidianos }\end{array}$ \\
\hline
\end{tabular}




\subsection{Percepções sobre a construção curricular na escola}

A parceria interinstitucional entre universidade e as escolas do município de Niterói firmada para o desenvolvimento desta pesquisa, inaugurou possibilidades de questionamentos entre as Diretrizes, os Referenciais Curriculares e Didáticos para a EJA instituída pela Fundação Municipal de Educação de Niterói e o currículo praticado nas salas de aula.

Nas diretrizes curriculares do município de Niterói está presente a Portaria FME $N^{\circ}$ 087/2011, que institui o referencial curricular para o ensino fundamental e para a modalidade EJA, estabelecendo as metas de ensino do $1^{\circ}$ ao $4^{\circ}$ ciclo $^{5}$. Nesta pesquisa, o que foi definido como anos iniciais são aqueles correspondentes ao $1^{\circ}$ e $2^{\circ}$ ciclo.

No $4^{\circ}$ parágrafo do segundo artigo desta portaria, fica definida a organização do período letivo para a EJA, sendo este integrado por dois semestres com, um mínimo de, 400 horas distribuídas em 100 dias de efetivo trabalho es colar cada, exceto o $1^{\circ}$ ano do $1^{\circ}$ ciclo, que é constituído por um período letivo com, um mínimo de 800 horas distribuídas em 200 dias de efetivo trabalho escolar.

No inciso III do terceiro artigo está definida a idade mínima de 15 anos para a matrícula na modalidade de ensino EJA. Apesar desta idade mínima, a maioria das matrículas era de adultos e idosos nos anos iniciais, o que por si só, esta já seria uma questão importante para se pensar no currículo.

No quarto artigo da Portaria FME N 085/2011, os referenciais curriculares e didáticos são definidos em três eixos temáticos de estudo e pesquisa: I - Linguagens; II - Tempo e Espaço; e III - Ciências e Desenvolvimento Sustentável. O artigo sétimo direciona o trabalho no eixo III:

Art. $7^{\circ}$ : No Eixo Ciências e Desenvolvimento Sustentável serão priorizadas a valorização dos saberes científicos e suas relações com os outros saberes; articulados à responsabilidade socioambiental e ao desenvolvimento sustentável. Os conteúdos curriculares desse eixo ajudam o aluno com o cuidado do corpo e da saúde, além de levá-los a analisarem as relações existentes entre os seres humanos, os seres vivos e entre estes e o ambiente, propiciando a valorização da ação consciente e da percepção global, de respeito à necessidade de uma intervenção qualificada com visão para a preservação ambiental. Também pretende contribuir para a

\footnotetext{
${ }^{5} \mathrm{O} 1^{\circ}$ Ciclo da Educação Fundamental equivale aos três primeiros anos de estudo (do $1^{\circ}$ ao $3^{\circ}$ ano), o $2^{\circ}$ ciclo equivale ao $4^{\circ}$ e $5^{\circ}$ anos, o $3^{\circ}$ ciclo equivale ao $6^{\circ}$ e $7^{\circ}$ anos e o $4^{\circ}$ ciclo equivale ao $8^{\circ}$ e $9^{\circ}$ anos.
} 
formação de sua identidade no contato com a pluralidade cultural, revelada em formas diferenciadas de origem e aproveitamento dos conhecimentos científicos possibilitados por exploração de situações problema, ainda que, precisando de apoio de materiais concretos para que, de forma progressiva, realizem abstrações e desenvolvam o raciocínio lógico e científico.

Durante o período de observação das práticas pedagógicas realizadas nos anos iniciais da EJA, diversos apontamentos sobre o terceiro eixo apareceram nos diários de campo, se destacando a dicotomia entre o que as Diretrizes e Referenciais Curriculares sugeriam e como de fato aparecia no currículo da escola. Nesse sentido, durante o planejamento das intervenções ativas, a presença de três pontos importantes do artigo sétimo da portaria FME Nº85/2011 foram rotineiramente incentivados no processo de elaboração das atividades práticas/experimentais: i) as relações dos saberes científicos com outros saberes; ii) a valorização de ações socioambientais conscientes; e iii) o uso de temas geradores de interesse dos estudantes da EJA para suscitar situações problemas a serem exploradas coletivamente.

Destaco, portanto neste momento, que mesmo com o incentivo para que os docentes da EJA considerassem esses pontos na organização de suas práticas pedagógicas, a metodologia de ensino e aprendizagem definidos para cada atividade, na maioria das vezes não abarcava concomitantemente todos eles, como especificado melhor na Tabela 3.

Ao inserir o ensino de Ciências através das atividades práticas/experimentais nos anos iniciais da EJA, a organização do currículo executado foi revolvida, permitindo que novas concepções fossem bem recebidas e viabilizadas pelos professores atuantes nesta modalidade de ensino.

Tanto a articulação entre os três pontos destacados acima, quanto a sua representação no processo educativo da EJA, guiou a proposta de reconstrução do currículo nas escolas e aparecem mais claramente nas falas dos professores ${ }^{6}$ que foram transcritas e utilizadas na elaboração dos relatos de experiência conforme apresentadas abaixo (BEIRAL, 2018; BEIRAL et al, 2019):

As atividades de Ciências ajudam sim, e muito! Só de conseguir fazer eles se interessarem por palavras e sentidos novos já é muita coisa! Eles no início têm dificuldades até para falar as palavras, como microscópio, por exemplo, depois que termina a aula de Ciências eles já querem ler e es-

\footnotetext{
${ }^{6}$ Estes dados são inéditos, estão sendo apresentados pela primeira vez neste artigo.
} 
crever a palavra microscópio! (Professora pedagoga da Escola Municipal Francisco Portugal Neves há 8 anos atuando nos anos iniciais da EJA de Niterói)

A inserção deste projeto aqui para a nossa EJA trás contribuições imensuráveis. Na medida em que leva a reflexão e registro das atividades e também dialogando com outras áreas de conhecimento os estudantes vão se sentindo pertencentes ao mundo que os cerca. (Professora pedagoga há 7 anos no município de Niterói e há 3 anos na EJA da Escola Municipal Maestro Heitor Villa Lobos).

Trazer questionamentos sobre os impactos das ações dos estudantes para o meio ambiente e fazê-los pensar que suas escolhas podem interferir na sua própria vida, faz este projeto ser superinteressante nesse sentido. Ainda tem o fato de a gente professor aprender mesmo como tornar os conteúdos dinâmicos e articulados. Nunca tinha pensado nisso. Para a EJA isso faz diferença. (Professora pedagoga da Escola Municipal Helena Antipoff há 5 anos atuando nos anos iniciais da EJA).

Nunca participei de projeto aqui na escola que os alunos da EJA fossem tão valorizados, as atividades têm coisas do dia a dia deles, eles que falam quais são seus interesses em Ciências, trazem questões... Interessante ver como que o conhecimento adquirido a partir da experiência de vida dos alunos vai se transformando em conteúdos curriculares, sem eles perceberem. (Professora pedagoga da Escola Municipal Honorina de Carvalho, atua na EJA há 11 anos).

Ainda sobre a Portaria FME $N^{\circ}$ 085/2011, no seu artigo décimo, fica definido que para a EJA as ações pedagógicas serão desenvolvidas de acordo com os eixos temáticos apresentados anteriormente e através do desenvolvimento de projetos educacionais e temas geradores, no sentido de favorecer a construção de novos conhecimentos a partir da relação dialógica entre a apropriação de conceitos e a prática no cotidiano, por intermédio do educador.

Chanceladas por este artigo, as ações de intervenção ativa nos anos iniciais da EJA, fomentadas pelo levantamento de temas geradores revelados nas falas dos alunos, permitiu perceber a importância do currículo construído coletivamente na escola guardar relações com o cotidiano destes estudantes.

Entre os temas geradores capturados dos cadernos de campo (BEIRAL, 2018; BEIRAL et al, 2019) estão aqueles que expressam as vivências dos 
alunos no seu ambiente de trabalho, nas atividades domésticas, nos cuidados com a sua saúde e da sua família, e aquelas que refletem preocupação com uma alimentação saudável e com o meio ambiente, como apresentado a seguir:

Quando o ovo está estragado ou cozido ele boia, tenho curiosidade em saber sobre isso. (Estudante, mulher de 61 anos, empregada doméstica, do $1^{\circ}$ ciclo da EJA, Escola Municipal João Brasil).

Não consigo entender como as fraldas descartáveis não deixam a urina do bebê vazar!(Estudante, mulher de 35 anos, babá, do $2^{\circ}$ ciclo da EJA, Escola Municipal Altivo Cesar).

Tenho pressão alta, então preciso vigiar o sal na comida. Quando o feijão fica salgado, o jeito é cortar umas batatas e colocar para cozinhar mais um pouquinho junto do feijão. (Estudante, mulher de 50 anos, do lar, do $2^{\circ}$ ciclo da EJA, Escola Municipal Doutor Alberto Francisco Torres).

Amo o verão, mas no verão chove muito, fico com medo porque vi tudo sendo arrastado no Morro do Bumba aqui em Niterói, não dá para esquecer. (Estudante, homem de 57 anos, pedreiro, do $1^{\circ}$ ciclo da EJA, Escola Municipal Francisco Portugal Neves).

\subsection{Percepções sobre a apropriação de conceitos científicos rumo ao discurso científico}

A apropriação do discurso científico, nesta pesquisa, foi entendida como a capacidade de ler, escrever e comunicar-se usando a linguagem da Ciência (FANG, 2006) em diversas situações do dia a dia dos estudantes da EJA. Nesse sentido, entender os conceitos científicos básicos dos fenômenos a serem explicados é fundamental para o progresso da aquisição do discurso científico.

As práticas pedagógicas desenvolvidas nesta pesquisa como facilitadoras para a aquisição dos conceitos científicos não objetivaram, portanto, motivar os estudantes a se tornarem cientistas ou absorverem todo o conhecimento da área. Seu propósito era apenas apresentar possibilidades de acesso a um conjunto de ações que caracterizam a cultura científica, definida por Yamada \& Motokane (2013) não somente como a habilidade para ler e escrever na linguagem científica, mas especialmente de formular questões, explicá-las e entender os fenômenos envolvidos - fazendo, desta forma, que os sujeitos se sintam ca- 
pazes de aplicá-la em outras situações usando argumentos consolidados no campo científico.

Entre as ações utilizadas que contribuíram para a apropriação de conceitos científicos estão a própria realização das atividades práticas/experimentais, a organização de Feiras de Ciências, além da visitação a espaços de divulgação científica da região. Estas ações proporcionaram aos estudantes da EJA a criação de um ambiente de renegociação entre suas crenças e conhecimento do senso comum com conceitos científicos. Neste sentido, buscando identificar a apropriação dos conceitos científicos pelos estudantes da EJA, foram evidenciadas algumas falas dos mesmos, registradas ao longo das atividades práticas/experimentais desenvolvidas e relacionados também os termos científicos que apareceram nos resumos da $2^{a}$ Feira de Ciências da EJA de Niterói $\left(2^{a}\right.$ FECEJA/Niterói) - esta Feira foi realizada ao final de dois anos de atividades nas escolas.

Para exemplificar, apresento as falas de três alunos de escolas diferentes (BEIRAL, 2018; BEIRAL et al, 2019), identificando os termos utilizados e os elementos que apontam para a apropriação de conceitos científicos e a sua utilização no cotidiano.

Estudante E1 - Quando trabalhei de lanterneiro em São Paulo e com pintura de carros, ganhava mais dinheiro. Os carros lá ficam com a pintura russa bem rápido. Eu recuperava todos, mas de vez em quando a mesma pessoa voltava com o mesmo carro, eu acho que o ar era muito poluído e grudava na pintura (homem de 52 anos, lanterneiro, do $1^{\circ}$ ciclo da EJA, Escola Municipal Professora Maria de Lourdes Barbosa Santos).

Estudante E2 - Eu consigo deixar a roupa branca bem clarinha quando eu lavo, mas preciso usar um sabão em pó bom e colocar a roupa para quarar. Só que tem um problema, o sabão em pó bom é mais caro, será por quê? Não devemos usar água sanitária, a roupa pode rasgar. (mulher de 48 anos, cozinheira e faxineira, do $2^{\circ}$ ciclo da EJA, Escola Municipal Professor Paulo de Almeida Campos).

Estudante E3 - Não é recomendado usar roupa preta no verão e sim roupa branca, não entendo muito bem, mas sei que sinto menos calor com roupas claras. (mulher de 44 anos, cozinheira e faxineira, do $2^{\circ}$ ciclo da EJA, Escola Municipal Helena Antipoff). 


\subsubsection{Correspondência das falas com as atividades práticas/experimen- tais}

Nestas falas é perceptível o uso de termos de senso comum pelos três estudantes para explicar fenômenos científicos observados em suas vivências cotidianas, porém sem estabelecer relações, ou mesmo, desconhecendo os conceitos científicos subjacentes aos fenômenos identificados, ainda que tais estudantes tivessem uma densa relação com o mundo que os cerca.

Partindo dessas falas e dos termos mais recorrentes foram selecionados os temas geradores para o desenvolvimento das atividades práticas/experimentais, através das quais, conceitos científicos relacionados às situações problema mencionadas eram abordados.

A Tabela 4 apresenta as atividades práticas/experimentais resultantes dos temas geradores, bem como os conceitos científicos a eles relacionados.

\begin{tabular}{|c|c|c|c|}
\hline \multicolumn{4}{|c|}{$\begin{array}{l}\text { TABELA 4. Atividades práticas/experimentais resultantes dos temas gerado- } \\
\text { res, bem como os conceitos científicos a eles relacionados }\end{array}$} \\
\hline Estudante & Temas geradores & $\begin{array}{l}\text { Conceito cien- } \\
\text { tífico }\end{array}$ & $\begin{array}{c}\text { Atividades práticas } / \text { ex- } \\
\text { perimentais }\end{array}$ \\
\hline E1 & $\begin{array}{c}\text { "pintura russa" } \\
\text { "ar era muito poluído" } \\
\text { "grudava na pintura" }\end{array}$ & $\begin{array}{l}\text { Reação química de } \\
\text { corrosão }\end{array}$ & Formação \\
\hline E2 & $\begin{array}{l}\text { "sabão em pó bom" } \\
\text { "roupa para quarar" } \\
\text { "a roupa pode rasgar" }\end{array}$ & \begin{tabular}{|c|}
$\begin{array}{c}\text { Composição quí- } \\
\text { mica da matéria e } \\
\text { suas interações }\end{array}$ \\
\end{tabular} & $\begin{array}{c}\text { Reações químicas espontâ- } \\
\text { neas, dependentes de } \\
\text { energia e substratos }\end{array}$ \\
\hline E3 & $\begin{array}{c}\text { "roupa preta" } \\
\text { "roupa branca" } \\
\text { "sinto menos calor" }\end{array}$ & $\begin{array}{c}\text { Cor e pigmento } \\
\text { "cor e pigmento } \\
\text { significam a mes- } \\
\text { ma coisa?" }\end{array}$ & $\begin{array}{l}\text { Mistura de cores - Disco } \\
\text { de Newton; Ausência de } \\
\text { cor; Cor refletida e cor ab- } \\
\text { sorvida }\end{array}$ \\
\hline
\end{tabular}

\subsubsection{Transformação dos termos identificados nas falas em conceitos ci- entíficos}

A preocupação existente ao se realizar as atividades práticas/experimentais com os alunos foi de não fazer a experimentação como um fim em si mesma, que os estudantes pudessem utilizar os conceitos relacionados às mesmas aplicando-os em outras situações semelhantes (AGOSTINI; DELIZOICOV, 2000). 
Com este propósito foi definido que os experimentos inscritos na Feira não poderiam repetir aqueles realizados durante as atividades de intervenção dos integrantes do NAEB nas aulas. Os estudantes da EJA deveriam formar grupos e definir o tema do trabalho para a Feira, de acordo com seus interesses, utilizando materiais simples, os quais pudessem manusear e explicar os resultados obtidos, se valendo de conceitos científicos apreendidos.

A Tabela 5 apresenta os temas dos trabalhos inscritos na $2^{\mathrm{a}}$ FECEJA/Niterói pelos grupos dos quais participaram os estudantes E1, E2 e $\mathrm{E} 3$, respectivamente.

\begin{tabular}{c|c|c|c|}
\hline TABELA 5. & \multicolumn{2}{c|}{ Temas dos trabalhos inscritos na $2^{\mathbf{a}}$ FECEJA/Niterói } \\
\hline $\begin{array}{c}\text { Participante do } \\
\text { grupo }\end{array}$ & $\begin{array}{c}\text { Projeto apresentado na } \\
\text { Feira }\end{array}$ & $\begin{array}{c}\text { Desenvolvimento do } \\
\text { projeto na Feira }\end{array}$ & Conceito científico \\
\hline E1 & $\begin{array}{c}\text { Tirar ferrugem nunca foi divertido } \\
\text { tão }\end{array}$ & $\begin{array}{c}\text { Levantar formas de } \\
\text { tirar ferrugem da } \\
\text { roupa }\end{array}$ & Reações de corrosão \\
\hline E2 & $\begin{array}{c}\text { O que temos em casa que } \\
\text { funciona melhor para } \\
\text { limpar? }\end{array}$ & $\begin{array}{c}\text { Utilização de produ- } \\
\text { tos naturais para lim- } \\
\text { peza da casa }\end{array}$ & $\begin{array}{c}\text { Composição química } \\
\text { e suas interações }\end{array}$ \\
\hline E3 & $\begin{array}{c}\text { Saboreie com os olhos, } \\
\text { além do paladar! }\end{array}$ & $\begin{array}{c}\text { Como manter a co- } \\
\text { loração verde escura } \\
\text { do brócolis cozido }\end{array}$ & Cor e pigmento \\
\hline
\end{tabular}

A relação com o cotidiano se destaca, devido à forte marca das questões envolvidas com a atuação profissional dos estudantes nos resumos dos projetos. O estudante cuja profissão era lanterneiro (E1), direcionou o seu trabalho para o entendimento das reações químicas da ferrugem. A estudante E2 que se declarou faxineira, apresentou uma proposta que envolvia a utilização de produtos naturais e a mistura destes para a limpeza de diversas superfícies. Já a estudante $\mathrm{E} 3$ desenvolveu um projeto relacionado a técnica culinária.

Os conceitos científicos utilizados nos trabalhos apresentados pelos estudantes na Feira foram os mesmos das atividades práticas/experimentais desenvolvidas em aula, porém recontextualizados para o objetivo de cada projeto.

A percepção foi que os estudantes conseguiram articular os conceitos científicos emergidos nos processos de intervenção nas aulas, se apropriando dos mesmos, ao utilizarem-nos em situações diferentes das apresentadas anteriormente, mas que as suas aplicações eram pertinentes.

Isso sugere que se for proporcionado aos alunos dos anos iniciais da EJA, acesso à cultura científica que se articule com o seu cotidiano, estes são 
capazes de desenvolverem a alfabetização científica. Tais resultados apontam também para a compreensão da relevância da alfabetização científica como potencializadora da consciência de cidadania por parte dos estudantes de EJA (CHASSOT, 2003).

\section{Considerações Finais}

O corpus de análise da pesquisa envolveu: (i) a formação docente inicial e continuada, (ii) a investigação da prática docente em Ciências, (iii) o desenvolvimento de estratégias didáticas para a execução interdisciplinar das atividades práticas/experimentais, (iv) a construção curricular na escola e (v) a apropriação de conceitos científicos pelos alunos da EJA. Para isso, apostou-se no diálogo com as escolas, na observação das práticas realizadas pelos professores e no planejamento de atividades práticas/experimentais voltadas ao cotidiano dos estudantes.

Das pautas colocadas como meta para o desenvolvimento da pesquisa e que resultou neste escrito, foi percebido que a pesquisa movimenta a formação inicial e continuada, contribuindo para uma formação diferenciada dos licenciandos em Pedagogia, e tira os licenciandos em Ciências Biológicas de uma comodidade que até então não era reconhecida como tal, mas sim como algo que não os pertencia profissionalmente - lecionar na EJA e partilhar aprendizados próprios da sua formação com os pedagogos.

$\mathrm{Na}$ formação continuada, a pesquisa destaca a importância da articulação universidade/escola para a proposição de políticas públicas, apresentando caminhos para que os professores atuantes nos anos iniciais da EJA repensem as Diretrizes e os Referenciais Curriculares para esta modalidade de ensino em suas práticas pedagógicas, de forma a reorganizar o currículo com um olhar menos segregador e mais integrador para o ensino de Ciências a partir do uso de atividades práticas/experimentais.

As narrativas das práticas pedagógicas escolares desenvolvidas motivam a construção de argumentos para novas pesquisas em Ciências numa modalidade de ensino marginalizada, porém persistente no Brasil.

Devido aos desafios impostos pela EJA, esta pesquisa proporcionou uma ampla produção de materiais resultantes de diversas adaptações das atividades práticas/experimentais, revelou mudanças de postura do professor, renovação de estratégias e reorganização de conteúdos tornando o ensino destes 
mais dinâmicos, interdisciplinares e em consonância com o cotidiano dos estudantes da EJA.

Estes destaques da pesquisa confirmam o processo de produção do conhecimento escolar que pode ser o alicerce para subsidiar a reconstrução ou a construção contínua do currículo neste espaço como proposto por Veiga (2002, p. 7).

Perceber não significa confirmar impactos, porém, com a continuidade desta pesquisa e com a ampliação de participantes institucionais (Instituições de Ensino Superior e da Educação Básica) e profissionais, os impactos surgirão. A iniciativa tomada por este projeto já está estabelecida como geradora de outros novos projetos semelhantes no estado do Rio de Janeiro.

\section{Referências}

AGOSTINI, V. W.; DELIZOICOV, N. C. A experimentação didática no ensino fundamental: impasses e desafios. In: $7^{\circ}$ ENCONTRO NACIONAL DE PESQUISA EM EDUCAÇÃO EM CIÊNCIAS. 2009, Florianópolis. Anais..., Florianópolis, ABRAPEC, 2009. p 1-12.

BEIRAL, H. J. V et al. Possibilidades de integração disciplinar no curso de Licenciatura em Ciências Biológicas a partir da criação do Núcleo de Apoio Experimental em Bioquímica para o ensino de Ciências e Biologia (NAEB). Revista de Ensino de Biologia da Associação Brasileira de Ensino de Biologia (SBEnBio). Maringá, n.1, v. 9,p. 7006 - 7015, 2016.

BEIRAL, H. J. V. O uso da experimentação escolar em ensino de Ciências como prática pedagógica na Educação de Jovens e Adultos (EJA). 2017. Relatório Técnico (Pós-doutorado) - Universidade Federal Fluminense, Programa de Pós Graduação em Educação, Niterói, RJ. Disponível em: <http://ppgeducacao.sites.uff.br/pos-doutorado>. Acesso em 28 out. 2020.

O experimento do meu dia-a-dia está na sala de aula: propostas de atividades práticas em Ciências para os anos iniciais da educação de jovens e adultos. 1. ed. São Gonçalo: FFP/UERJ, 2018. v. 1. 60f.

et al. A apropriação de conceitos científicos nos anos iniciais da EJA: evidências das relações entre cotidiano e atividades práticas/experimentais. In: 39a REUNIÃO NACIONAL DA ANPED. EDUCAÇÃO PÚBLICA E PESQUISA: ATAQUES, LUTAS E RESISTÊNCIAS. 2019, Niterói, Rio de Janeiro, Anais..., Rio de Janeiro, 2019. p. 1-3. 
BOGDAN, R. C.; BIKLEN, S. K. Investigação qualitativa em educação. Tradução Maria João Alvarez, Sara Bahia dos Santos e Telmo Mourinho Baptista. Porto: Porto Editora, 1994.

BRASIL. Fundação Municipal de Educação. Atos do Presidente. Portaria FME $\mathrm{N}^{\circ}$ 085, de 12 de fevereiro de 2011. Institui na Rede Municipal de Ensino, as Diretrizes e os Referenciais Curriculares e Didáticos: Uma Construção Coletiva, para a Educação Infantil, o Ensino Fundamental Regular e a Educação de Jovens e Adultos e dá outras providências. A Tribuna, Niterói, Rio de Janeiro, 12 fev. 2011. Seção 1. p 1-4.

CACHAPUS, A. et al. Do estado da arte da pesquisa em educação em Ciências: linhas de pesquisa e o caso "Ciência-Tecnologia-Sociedade". Alexandria Revista de Educação em Ciência e Tecnologia, Florianópilis, v. 1, n. 1, p. 27 49, 2008.

CAMArgo, P. S. A. S. Percepções de Alunos Jovens e Adultos sobre o processo de Ensino-Aprendizagem. 2005. 115f. Dissertação (Mestrado) Universidade Estadual de Campinas, Faculdade de Educação, Campinas, SP. Disponível em: < http:/ / www.repositorio.unicamp.br/handle/REPOSIP/ 253043>. Acesso em: 5 ago. 2018.

CARVALHO, A. M. P.; GIL-PÉRES, D. Formação de professores de ciências: tendências e inovações. (Coleção Questões da Nossa época; v.26) 8. ed. São Paulo: Cortez, 2006.

CHASSOT, A. Alfabetização científica: uma possibilidade para a inclusão social. Revista Brasileira de Educação [online], 2003, n.22, p 89-100.

DOURADO, L. (2001). Trabalho Prático (TP), Trabalho Laboratorial (TL), Trabalho de Campo (TC) e Trabalho Experimental (TE) no Ensino das Ciências - contributo para uma clarificação de termos. In: VERÍSSIMO, A.; PEDROSA, M. A.; RIBEIRO, R. Ensino Experimental das Ciências. 1. ed. 3. v. (Re)pensar o Ensino das Ciências.

FAHL, D. D. Marcas do ensino escolar de ciências presentes em museus e centros de ciências: um estudo da Estação Ciência - São Paulo e do Museu Dinâmico de Ciências de Campinas MDCC. 2003. 201f. Dissertação (mestrado) - Faculdade de Educação, Universidade Estadual de Campinas, Campinas, 2003. Disponível em: <http://www.repositorio.unicamp.br/handle/REPOSIP/253629>. Acesso em: 3 ago. 2018. 
FANG, Z. The language demands of science reading in middle school. International Journal of Science Education [online], v. 28, n. 5, p. 491-520, 2006.

GARCIA, R. M.; da SILVA, M. P. EJA, diversidade e inclusão: reflexões impertinentes. João Pessoa: Editora UFPB, 2018.

GOMES, M. O. Formação de professores na Educação Infantil. São Paulo: Cortez, 2009.

LIMA, T. C. S., et al. A documentação no cotidiano da intervenção dos assistentes sociais: algumas considerações acerca do diário de campo. Textos \& Contextos, Porto Alegre, v. 6, n. 1, p. 93-104, jan./jun. 2007.

MEGID, J. N. Tendências da pesquisa acadêmica sobre o ensino de ciências no nível fundamental. 1999. 365f. Tese (doutorado) - Faculdade de Educação, Universidade Estadual de Campinas, Campinas, 1999.

MOURA, T. M. M. Formação de Educadores de Jovens e Adultos: Realidade, desafios, e perspectivas atuais. Práxis Educacional, v. 5, n. 7, p. 45-72, 2009.

MUENCHEN, C.; AULER, D. Configurações curriculares mediante o enfoque CTS: desafios a serem enfrentados na educação de jovens e adultos. Ciência $\boldsymbol{\&}$ Educação, Bauru, v. 13, n. 3, p. 421-434, 2007.

NASCIMENTO, F. et al. O ensino de ciências no Brasil: história, formação de professores e desafios atuais. Revista HISTEDBR On-line, Campinas,v.10, n. 39, p. 225-249, set. 2010.

PERRENOUD, P. Práticas pedagógicas, profissão docente e formação: perspectivas sociológicas. Lisboa: Publicações Dom Quixote, 1997.

PICONEZ, S. C. B. Educação escolar de jovens e adultos: das competências sociais dos conteúdos aos desafios da cidadania. 5. ed. Campinas: $\mathrm{Pa}-$ pirus, 2006.

PRATA, R.; MARTINS, I. Ensino de ciências e educação de jovens e adultos: pela necessidade do diálogo entre campos e práticas. In: $5^{\circ}$ ENCONTRO NACIONAL DE PESQUISA EM EDUCAÇÃO EM CIÊNCIAS. 2005, Bauru. Anais... 2005. Belo Horizonte: ABRAPEC, 2005. p 1-11.

ROCHA, M. L. Psicologia e as práticas institucionais: a pesquisa-intervenção em movimento. Psico, Porto Alegre, v. 37, n. 2, p. 169-174, maio/ago. 2006. 
SÁ, L. P. et al. Análise das Pesquisas sobre EJA nos Encontros Nacionais de Pesquisas em Educação em Ciências. In: $8^{\circ}$ ENCONTRO NACIONAL DE PESQUISA EM EDUCAÇÃO EM CIÊNCIAS. , 2011, Campinas. Anais... 2011. Campinas: ABRAPEC, 2011. p 1-12.

VEIGA NETO, A. De Geometrias, Currículo e Diferenças. Revista Educação e Sociedade, Dossiê Diferenças.v. 23, n.79, p. 163-186, ago. 2002.

YAMADA, M.; MOTOKANE, M. T. Alfabetização Científica: apropriações discursivas no desenvolvimento da escrita de alunos em aula de Ecologia. Revista Práxis, Volta Redonda, v. 5, n. 10, p. 29-40, 2013. 
